\title{
Perfusion index and pleth variability index in the first hour of life according to mode of delivery
}

\author{
Şule Yiğit ${ }^{1}$, Şahin Takc1², Davut Bozkaya ${ }^{3}$, Murat Yurdakök ${ }^{1}$ \\ ${ }^{1}$ Division of Neonatology, Department of Pediatrics, Hacettepe University Faculty of Medicine, Ankara; ${ }^{2}$ Division of \\ Neonatology, Department of Pediatrics, Gaziosmanpasa University Faculty of Medicine, Tokat; ${ }^{3}$ Division of Neonatology, \\ Zekai Tahir Burak Maternity Training Hospital, Ankara, Turkey. \\ E-mail: suleyigit6@gmail.com or suley@hacettepe.edu.tr
}

Received: 14th September 2017, Accepted: 2nd December 2017

\begin{abstract}
SUMMARY: Yiğit Ş, Takcı Ş, Bozkaya D, Yurdakök M. Perfusion index and pleth variability index in the first hour of life according to mode of delivery. Turk J Pediatr 2018; 60: 421-425.

Perfusion index (PI) is a relative assessment of the pulse strength at the monitoring site. The plethysmographic variability index (PVI, pleth variability index) is a noninvasive and continuous measure of the dynamic change in PI that occurs during respiratory cycles. In this study PI and PVI changes were compared in babies born with cesarean section $(\mathrm{C} / \mathrm{S})$ or spontaneous vaginal delivery (SVD); 125 healthy term infants were monitored with pulse oxymeter after first ten minutes of life. Data were recorded from this monitor on a personal computer and analyzed by generalized estimating equations (GEE) method. Pulse rate was lower in babies born via SVD. Perfusion index were higher in $\mathrm{C} / \mathrm{S}$ group. Pleth variability index were higher in $\mathrm{C} / \mathrm{S}$ group. Higher pulse rate, PI and PVI values in babies born via $\mathrm{C} / \mathrm{S}$ may be indicative of more significant hemodynamic changes in these infants during early transitional period after birth.
\end{abstract}

Key words: birth, cesarean section, newborn, pleth variability index, pulse oximeter, transitional period.

Pulse oximetry is a widely used device for monitoring arterial oxygen saturation $\left(\mathrm{SpO}_{2}\right)$ in neonatal intensive care units and delivery rooms. The signal comprises two components: one is arterial and pulsatile, and the other is non-pulsatile and originates from other light absorbing tissues (connective tissue, bone, and venous blood). Oxygen saturation is an analysis of pulsatile component. Perfusion index (PI) is the ratio of the pulsatile component (arterial compartment) to the non-pulsatile component of the light reaching the device's detector. PI is a scaled numerical value calculated as the percentage between the infrared pulsatile [alternating current (AC)] signal and the nonpulsatile [direct current (DC)] infrared signal $(\mathrm{PI}=[\mathrm{AC} / \mathrm{DC}] \times 100)$, reflecting the amplitude of the pulse oximetry plethysmographic waveform. Median value of PI is determined as $1.7 \%$ in 10,000 healthy newborn infants. PI reflects changes in peripheral blood flow and a PI value of lower than 1.24 has been shown to be a predictor for assessing the severity of neonatal illness. Changes in PI could also occur as a result of the local vasoconstriction (decrease in PI) or the vasodilatation (increase in PI) on the skin at the monitoring site.

The plethysmographic variability index (PVI, pleth variability index) is a noninvasive and continuous measure of the dynamic change in PI that occurs during one or more respiratory cycles:

PVI $=([$ PImax-PImin $] /$ PImax $) \times 100$

PVI is a new parameter and it can detect hemodynamic changes in spontaneously breathing newborns. It was shown that PVI may serve as a valid predictor of volume responsiveness in mechanically ventilated newborn infants during surgery. PVI levels were found to be higher in infants with hypotension due to volume loss.

It is well known that cesarean section $(\mathrm{C} / \mathrm{S})$, compared with vaginal delivery, is more likely 
to be associated with an increased risk of some potential respiratory morbidities.

In this study we aimed to compare PI and PVI changes in the first hour of life in babies born with $\mathrm{C} / \mathrm{S}$ or spontaneous vaginal delivery (SVD).

\section{Material and Methods}

Healthy term infants born between 20132014, in Hacettepe University Hospitals were included in the study. The infants resuscitated at birth were excluded from study. Other exclusion criteria were congenital malformations, chromosomal abnormalities, perinatal asphyxia, congenital heart disease, respiratory problems, chorioamnionitis and sepsis. Infants were monitored with pulse oxymeter after first ten minutes of life. The sensor was placed in the right hand after receipt of informed parental consent. PI, PVI, oxygen saturation and pulse rate were captured in every 2 second for a duration of about $30 \mathrm{~min}$., using a Masimo signal extraction technology Radical-7 pulse-oximeter (Masimo Corp., Irvine, California, USA). Data were recorded from this monitor on a personal computer and analyzed by generalized estimating equations (GEE) method. The study was approved by the local ethics committee (no: GO 14/108-17).

\section{Statistical analysis}

Data were recorded from the monitor on a personal computer and analyzed by generalized estimating equations (GEE) method, with SPSS version 17.0(SPSS, Chicago, IL). Group differences were analyzed using Student's ttest or Chi-Square test for normally distributed data, or Kruskal-Wallis test for non-normally distributed data, with SPSS version 17.0. Results are expressed as mean \pm SD. $\mathrm{P}<0.05$ was considered statistically significant. Correlations were analyzed using Pearson or Spearman correlation coefficients.

\section{Results}

One hundred twenty five infants (79 males, 46 females) were included in the study. Mean gestational age and birth weight of the babies were $38.5 \pm 1.09$ week and 3,234 \pm 410 grams, respectively; $94(75.2 \%)$ of the babies were born via cesarean section while $24.8 \%$ were born via spontaneous vaginal delivery. Mean Apgar scores of the babies at five and ten minutes were $9.7 \pm 0.6$ and $9.9 \pm 0.1$, respectively. Table I shows demographic characteristics of infants according to delivery route. There was no statistical difference in birth weight, Apgar scores at five minutes, and sex between groups. Mean gestational age was slightly small in C/S group according to SVD group (38.3 weeks versus 38.9 weeks $\mathrm{p}=0.006$ ).

There was no statistical difference in $\mathrm{SpO}_{2}$ levels between $\mathrm{C} / \mathrm{S}$ and SVD groups; however $\mathrm{SpO} 2$ levels changed with time. SpO2 levels increased with time (Fig. 1).

Pulse rate was lower in babies born via SVD $(p<0.013)$. Pulse rate decreased with time in both of groups (Fig. 2). Apgar scores at five minutes were positively correlated with pulse rate $(\mathrm{r}=4.80, \mathrm{p}<0.001)$.

Perfusion index were higher in $\mathrm{C} / \mathrm{S}$ group $(p=0.010$; Fig. 3), birth weight was inversely correlated with PI $(\mathrm{r}=-0.05, \mathrm{p}=0.02)$ and, time were negatively correlated with PI $(r=-0.014$, $\mathrm{p}=0.01$ ).

Pleth variability index were higher in $\mathrm{C} / \mathrm{S}$ group $(p=0.03)$ (Fig. 4) and time were negatively correlated with PVI $(\mathrm{r}=-0.221, \mathrm{p}=0.001)$.

$\mathrm{SpO}_{2}$ was negatively correlated with pulse rate $(\mathrm{r}=-0.211, \mathrm{p}=0.001), \mathrm{PI}(\mathrm{r}=-0.111, \mathrm{p}=0.001)$ and PVI $(\mathrm{r}=-0.366, \mathrm{p}=0.001)$. Pulse rate was negatively correlated with $\mathrm{SpO}_{2}(\mathrm{r}=-0.211$, $\mathrm{p}=0.001)$, and positively correlated with PVI $(r=0.216, p=0.001)$. PI was negatively correlated with $\mathrm{SpO}_{2}(\mathrm{r}=-0.111, \mathrm{p}=0.001)$ but was positively correlated with PVI $(r=0.096$, $\mathrm{p}=0.001)$. PVI was positively correlated with PI $(r=0.096, p=0.001)$ and pulse rate $(r=0.0216$, $\mathrm{p}=0.001)$ and negatively correlated with $\mathrm{SpO} 2$ $(\mathrm{r}=-0.366, \mathrm{p}=0.001)$.

\section{Discussion}

Profound changes in the cardiovascular and pulmonary systems occur after delivery in response to removal of the placenta as the source of fetal gas exchange and nutrition. The transition from a fetus to a newborn is a complex adaptation. In this period important changes occur such as clearance of fetal lung fluid, surfactant secretion, pulmonary vasodilatation and initiation of regular breathing. At the same time cardiovascular alterations in blood flow and pressures occur. Most of these changes 


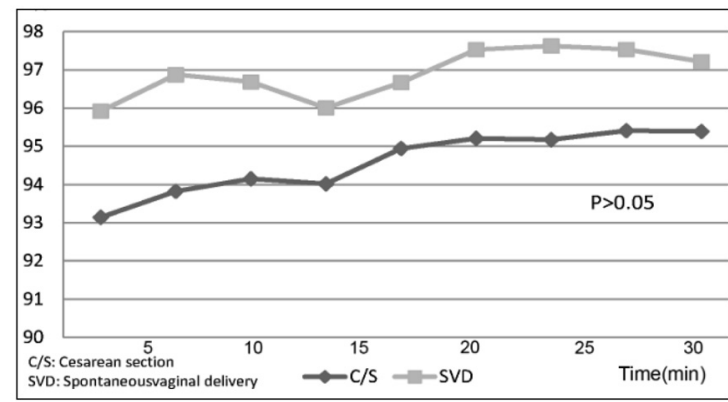

Fig. 1. SpO2 levels (\%) in infants born via cesarean section or spontaneous vaginal delivery.

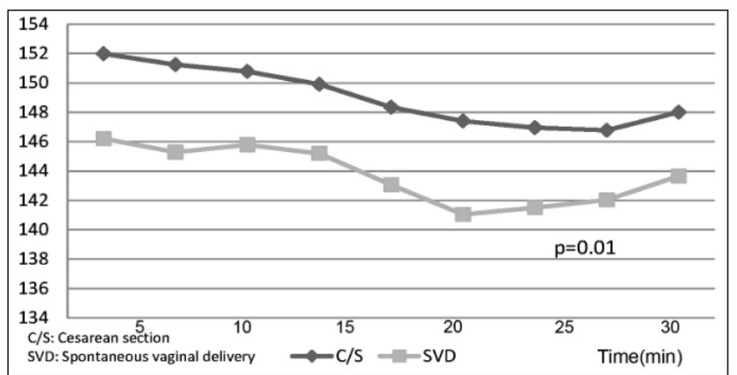

Fig. 2. Pulse rate $(/ \mathrm{min})$ in infants born via cesarean section or spontaneous vaginal delivery.

come out in the first hours of life.

We showed that $\mathrm{SpO}_{2}$ levels increase while pulse rate decreases with time within the first hour of life. It was reported that $\mathrm{SpO}_{2}$ increased progressively from $65 \%$ at one minute after birth to $97 \%$ at 17 minutes after birth in healthy 20 term infants. In our study infants were monitored at about ten minutes of life and $\mathrm{SpO} 2$ levels slightly continued to increase during half an hour. Lu et al. ${ }^{8}$ did not show any difference in $\mathrm{SpO}_{2}$ levels according to delivery mode in first ten minutes of life. However other studies determined that babies born via $\mathrm{C} / \mathrm{S}$ had lower $\mathrm{SpO}_{2}$ levels than babies born via SVD in first ten minutes of life.' In our study $\mathrm{SpO}_{2}$ levels, recorded after ten minutes of life during half an hour, were slightly higher in spontaneous vaginal group compared to $\mathrm{C} / \mathrm{S}$ group although it did not reach statistical significance (Fig. 1).

Pulse rate decreased during time while $\mathrm{SpO}_{2}$ increased, indicating stabilization. Pulse rate was between 146-147 in babies born SVD while around 152 in C/S group at the beginning of monitoring, and decreased with time, but the difference was preserved between groups.

PI values were higher in babies of $\mathrm{C} / \mathrm{S}$ group

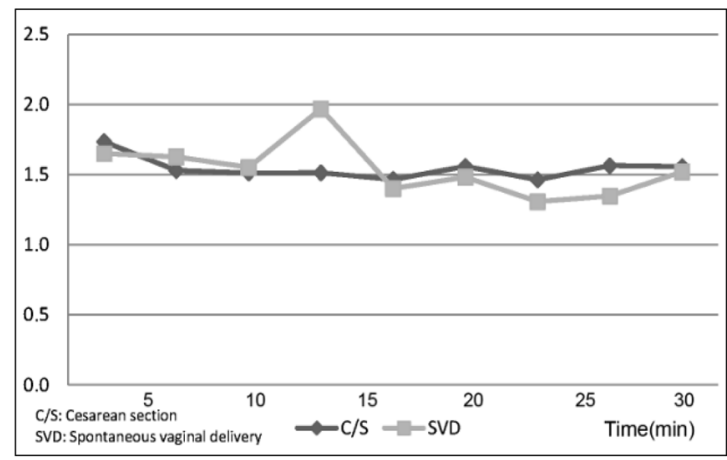

Fig. 3. Perfusion index (\%) in infants born via cesarean section or spontaneous vaginal delivery.

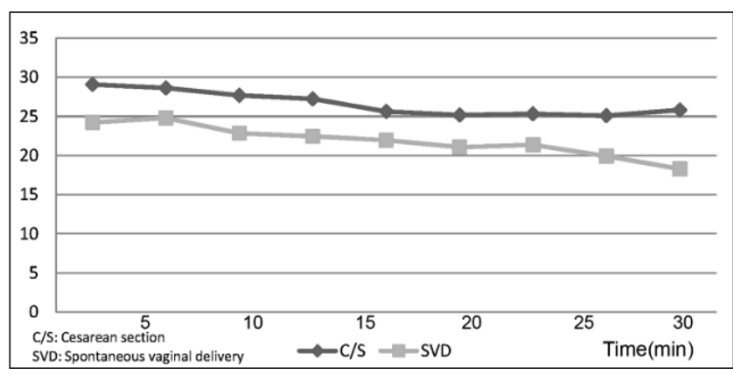

Fig. 4. Pleth variability index (\%) in infants born via cesarean section or spontaneous vaginal delivery.

than SVD group and decreased with time. It has been reported that in critically ill patients, a decreased PI underlines severity of illness. Neonatal studies are not sufficient to determine cut off values for severe illnesses in neonatal patients. One study ${ }^{2}$ suggested $1.24 \%$ as cut-off value while in another study ${ }^{1}$ the 5 th percentile of PI was determined as 0.70 in healthy term infants, indicating different study designs are needed to provide further validation for its use in clinical practice. It has been reported that one value of PI could be truly meaningless, but monitoring its trend can provide us important clinical information, especially because the PI is obviously affected by perfusion which can change in a brief period of time just by bending or moving an extremity. For this reason, it only makes sense to design studies with continuous monitoring and to choose epochs to record PI. In our study the infants were continuously monitored during half an hour and data were analyzed on computer and trends were obtained. PI values were obtained from $\mathrm{C} / \mathrm{S}$ and SVD groups that were not under values determined as cut off point in other studies. Decreases over time which determined in both of groups, may indicate 
Table I. Demographic Characteristics of the Infants According to Delivery Route.

\begin{tabular}{|c|c|c|c|}
\hline \multirow{2}{*}{ Characteristics } & \multicolumn{2}{|c|}{ Delivery route } & \multirow[b]{2}{*}{$\mathrm{p}$} \\
\hline & $\mathrm{C} / \mathrm{S}$ & SVD & \\
\hline Sex, male/female & $56 / 38$ & $23 / 8$ & 0.212 \\
\hline Gestational age, weeks & $38.3 \pm 1.0$ & $38.9 \pm 0.9$ & 0.006 \\
\hline Birth weight, grams & $3,224 \pm 430$ & $3,245 \pm 315$ & 0.806 \\
\hline Apgar score at $5 \mathrm{~min}$. & $9.7 \pm 1.1$ & $9.9 \pm 0.2$ & 0.228 \\
\hline
\end{tabular}

C/S: cesarean section, SVD: spontaneous vaginal delivery

that higher PI values may occur during early transitional period.

There are limited studies about PVI index in newborn period. In a study the median PVI value on the first day of life was found as $20 \%$, the $10^{\text {th }}$ and $90^{\text {th }}$ percentile cutoff values were $12 \%$ and $28 \%$, respectively. They also showed that PVI level was positively correlated with PI and pulse rate, while it was inversely correlated with oxygen saturation. Similarly, lowest and highest figures were $18 \%$ and $30 \%$ respectively and PVI was positively correlated with PI and pulse rate and negatively correlated with $\mathrm{SpO} 2$ in our study. In adult patients it was shown that PVI levels are important to detect dynamic changes in PI that occurs during one or more respiratory cycles and increases in hypotension due to volume loss.

Another study in preterm infants showed that PVI may be a new indicator of the cardiac preload, particularly in very preterm neonates who seem to be particularly dependent on altered loading conditions. All infants included in our study were healthy term infants and none of the infants had respiratory distress, hypotension or any illness. The only difference was delivery mode between groups. Higher PVI levels in babies born via $\mathrm{C} / \mathrm{S}$ indicate that these babies may have significant hemodynamic changes in the first hour of life compared to the infants born via spontaneous vaginal delivery.

Transitional changes during first hour of life were investigated in a study. ${ }^{7}$ They showed that significant changes in cardiac function, cerebral hemodynamics, and oxygenation during the first 20 minutes after birth and, that smaller changes continued through the first 48 hours after birth. They found a decrease in cerebral blood flow probably due to increased oxygen content of blood, a drop in heart rate, an increase in left stroke volume, and a trend toward increased left ventricular output during the first 20 minutes after birth, but no significant changes in right stroke volume or right ventricular output. Similarly, we found decrease in heart rate while the increase was determined in $\mathrm{SpO}_{2}$ at the same time. They did not investigate if there was any difference in these changes according to delivery route. Our study indicates that more significant hemodynamic changes may be experienced in babies born via cesarean section. However hemodynamic changes were not determined with echocardiography in our study, and also blood pressure levels were not monitored. More detailed studies including echocardiographic evaluation are needed to evaluate the reason of these hemodynamic differences between groups.

This study compares PI and PVI values in babies born via C/S and SVD in the first hour of life. Higher pulse rate, PI and PVI values in babies born via $\mathrm{C} / \mathrm{S}$ may be indicative of more significant hemodynamic changes in these infants during early transitional period after birth.

\section{Acknowledgments}

We thank Sevilay Karahan (Department of Biostatistics Hacettepe University) for her assistance with methodology and statistical analysis.

\section{REFERENCES}

1. Granelli Ad, Ostman-Smith I. Noninvasive peripheral perfusion index as a possible tool for screening for critical left heart obstruction. Acta Paediatr 2007; 96: 1455-1459.

2. De Felice C, Latini G, Vacca P, Kopotic RJ. The pulse oximeter perfusion index as a predictor for high illness severity in neonates. Eur J Pediatr 2002; 161: 561-562.

3. Hales JR, Stephens FR, Fawcett AA, et al. Observations on a new non-invasive monitor of skin blood flow. Clin Exp Pharmacol Physiol 1989; 16: 403-415. 
4. Bagci S, Müller N, Müller A, Heydweiller A, Bartmann P, Franz AR. A pilot study of the pleth variability index as an indicator of volume-responsive hypotension in newborn infants during surgery. J Anesth 2013; 27: 192-198.

5. Karlström A, Lindgren H, Hildingsson I. Maternal and infant outcome after caesarean section without recorded medical indication: Findings from a Swedish case-control study. BJOG. 2013; 120: 479-486.

6. Hillman NH, Kallapur SG, Jobe AH. Physiology of transition from intrauterine to extrauterine life. Clin Perinatol 2012; 39: 769-783.

7. Noori S, Wlodaver A, Gottipati V, McCoy M, Schultz $\mathrm{D}$, Escobedo M. Transitional changes in cardiac and cerebral hemodynamics in term neonates at birth. $\mathrm{J}$ Pediatr 2012; 160: 943-948.

8. Lu YC, Wang CC, Lee CM, et al. Reevaluating reference ranges of oxygen saturation for healthy full-term neonates using pulse oximetry. Pediatr Neonatol 2014; 55: 459-465.

9. Rabi Y, Yee W, Chen SY, Singhal N. Oxygen saturation trends immediately after birth. J Pediatr 2006; 148: 590-594.
10. Nuntnarumit P, Rojnueangnit K, Tangnoo A. Oxygen saturation trends in preterm infants during the first 15 min after birth. J Perinatol 2010; 30: 399-402.

11. Pinto Lima A, Beelen P, Bakker J. Use of a periphera perfusion index derived from the pulse oximetry signal as a noninvasive indicator of perfusion. Crit Care Med 2002; 30: 1210-1203.

12. Piasek CZ, Van Bel F, Sola A. Perfusion index in newborn infants: A noninvasive tool for neonatal monitoring. Acta Paediatr 2014; 103: 468-473.

13. Latini G, Dipaola L, De Felice C. First day of life reference values for pleth variability index in spontaneously breathing term newborns. Neonatology 2012; 101: 179-182.

14. Desebbe O, Boucau C, Farhat F, Bastien O, Lehot JJ, Cannesson M. The ability of pleth variability index to predict the hemodynamic effects of positive endexpiratory pressure in mechanically ventilated patients under general anesthesia. Anesth Analg 2010; 110: 792-798.

15. Vidal M, Ferragu F, Durand S, Baleine J, Batista-Novais AR, Cambonie G. Perfusion index and its dynamic changes in preterm neonates with patent ductus arteriosus. Acta Paediatr 2013; 102: 373-378. 